\title{
Hábitats da microbiota residente e aditivos equilibradores intestinais para aves de produção: revisão
}

\author{
Resident microbiota habitats and gut-balancing additives for poultry production: review \\ Hábitats de la microbiota residente y aditivos de equilibrio intestinal para la producción avícola: \\ revisión
}

Helia Sharlane de Holanda Oliveira

ORCID: https://orcid.org/0000-0002-4314-4827

Universidade Federal Rural de Pernambuco, Brasil E-mail: sharlaneho@yahoo.com

Gabriel Miranda Macambira

ORCID: https://orcid.org/0000-0002-0277-5286

Universidade Federal Rural de Pernambuco, Brasil

E-mail: gabriel.miranda.zootecnia@gmail.com

Ana Carolina Ferreira dos Santos

ORCID: https://orcid.org/0000-0003-0361-5222

Universidade Federal Rural de Pernambuco, Brasil E-mail: carolufrpe@ hotmail.com

Marilene dos Santos Maciel

ORCID: https://orcid.org/0000-0003-4234-9764 Universidade Federal Rural de Pernambuco, Brasil

E-mail: marilenemaciel123@hotmail.com

Chrislanne Barreira de Macêdo Carvalho

ORCID: https://orcid.org/0000-0003-0704-4949

Universidade Federal Rural de Pernambuco, Brasil

E-mail: chrislanne_carvalho@hotmail.com

Maria Aline Alves Mota

ORCID: https://orcid.org/0000-0001-7171-7648

Universidade Federal Rural de Pernambuco, Brasil E-mail: mariaaline168@gmail.com

Diana Valadares Pessoa

ORCID: https://orcid.org/0000-0002-1194-4985

Universidade Federal Rural de Pernambuco, Brasil E-mail: dianavaladares13@hotmail.com

Gabriela Duarte Silva

ORCID: https://orcid.org/0000-0001-9688-8881 Universidade Federal Rural de Pernambuco, Brasil

E-mail: gabrieladuarte1059127@gmail.com

Monique Aguiar Siqueira

ORCID: https://orcid.org/0000-0002-0367-855X

Universidade Federal Rural de Pernambuco, Brasil E-mail: moniqueaguiars@ hotmail.com 


\author{
Débora Marques Moraes Portela de Souza \\ ORCID: https://orcid.org/0000-0003-0114-8579 \\ Universidade Federal Rural de Pernambuco, Brasil \\ E-mail: debora.portela@live.com \\ Jéssica Berly Moreira Marinho \\ ORCID: https://orcid.org/0000-0002-3826-7670 \\ Universidade Federal Rural de Pernambuco, Brasil \\ E-mail: jessicaberlymm@gmail.com \\ Letícia Aline Lima da Silva \\ ORCID: https://orcid.org/0000-0002-4758-9890 \\ Universidade Estadual de Maringá, Brasil \\ E-mail: leticiaalinezoo@gmail.com \\ Vitor Magalhães de Mendonça Cunha Miranda \\ ORCID: https://orcid.org/0000-0001-7473-4398 \\ Universidade Estadual de Maringá, Brasil \\ E-mail: vitor.zootec01@gmail.com
}

\begin{abstract}
Resumo
A microbiota residente das aves de produção apresenta-se com uma grande variedade de microrganismos comensais e/ou mutualistas, que colonizam desde o papo, permeando através do proventrículo, ventrículo, intestino delgado e suas porções (duodeno, jejuno, íleo) e intestino grosso (cecos, cólon e reto). Atuam no metabolismo dos nutrientes da dieta gerando metabolitos importantes para o equilíbrio do microbioama intestinal e na preservação da parede tecidual dos órgãos intestinais, resultando em melhor aproveitamento dos nutrientes da dieta, bem como, maior produtividade animal. O conhecimento sobre esse ecossistema e como ele funciona, é de extrema importância, pois através de aditivos funcionais pode-se influenciar a microbiota intestinal, melhorando a absorção e o desempenho animal. Esta revisão bibliográfica tem como objetivo principal indicar os principais aspectos da microbiota intestinal das aves de produção e seus habitats e, alguns dos principais aditivos melhoradores de microbiota utilizados na nutrição animal para garantir a sanidade do ambiente intestinal das aves. A metodologia adotada foi um estudo descritivo, resultando em uma revisão bibliográfica embasada em artigos científicos mundiais.
\end{abstract}

Palavras-chave: Avicultura; Exigências nutricionais; Nutrientes; Trato gastrointestinal.

\begin{abstract}
The resident microbiota of poultry presents a great variety of commensal and/or mutualistic microorganisms, which colonize from the crop, permeating through the proventriculus, ventricle, small intestine and its portions (duodenum, jejunum, ileum) and large intestine (cecum, colon, and rectum). They act in the metabolism of nutrients in the diet, generating important metabolites for the balance of the intestinal microbiota and in the preservation of the tissue wall of the intestinal organs, resulting in better use of the nutrients in the diet, as well as greater animal productivity. Knowledge about this ecosystem and how it works is extremely important, since through functional additives it is possible to influence the intestinal microbiota, improving the absorption and animal performance. This literature review has as its main objective to indicate the main aspects of the intestinal microbiota of poultry and their habitats, and some of the main microbiota-enhancing additives used in animal nutrition to ensure the health of the poultry intestinal environment. The methodology adopted was a descriptive study, resulting in a literature review based on worldwide scientific articles.
\end{abstract}

Keywords: Poultry; Nutritional requirements; Nutrients; Gastrointestinal tract.

\title{
Resumen
}

La microbiota residente de las aves de corral presenta una gran variedad de microorganismos comensales y/o mutualistas, que colonizan el buche, permeando a través del proventrículo, el ventrículo, el intestino delgado y sus porciones (duodeno, yeyuno, íleon) y el intestino grueso (ciego, colon y recto). Actúan en el metabolismo de los nutrientes de la dieta, generando metabolitos importantes para el equilibrio de la microbiota intestinal y en la conservación de la pared tisular de los órganos intestinales, lo que resulta en un mejor aprovechamiento de los nutrientes de la dieta, así como en una mayor productividad de los animales. El conocimiento de este ecosistema y su funcionamiento es de extrema importancia, ya que a través de los aditivos funcionales es posible influir en la microbiota intestinal, mejorando la absorción y el rendimiento de los animales. Esta revisión bibliográfica tiene como objetivo principal indicar los principales aspectos de la microbiota intestinal de las aves de corral y sus hábitats, así como algunos de los principales aditivos potenciadores de la microbiota utilizados en la alimentación animal para garantizar la salud del entorno intestinal de las aves. La metodología adoptada fue un estudio descriptivo, que dio lugar a una revisión bibliográfica basada en artículos científicos de todo el mundo.

Palabras clave: Avicultura; Necesidades nutricionales; Nutrientes; Tracto gastrointestinal. 


\section{Introdução}

A microbiota intestinal corresponde ao conjunto de microrganismos comensais e/ou mutualistas do trato gastrointestinal, vivendo em equilíbrio com o seu hospedeiro. A importância destes agentes endógenos está fortemente ligada à mantença da homeostase do ambiente intestinal, renovação do epitélio intestinal, bem como, defesa contra os microorganismos patogênicos. A microbiota também está envolvida com a manutenção da motilidade intestinal e na absorção dos nutrientes provindos da dieta animal (Kogut, 2019; Feitosa et al., 2020).

A simbiose entre agente e hospedeiro tem grande relevância para o bem-estar e sanidade animal, afetando diretamente sobre a produção numa relação de ganho e perda. $\mathrm{Na}$ avicultura industrial, a manutenção da microbiota intestinal garante melhor aproveitamento nutricional dietético e desenvolvimento funcional das aves em tempo hábil (Celi, et al., 2018; Feitosa et al., 2020).

No entanto, fatores como erro de manejo, escolha de ingrediente de forma inadequada, condições ambientais que desencadeiam estresse nos animais, como temperaturas elevadas ou reduzidas demasiadamente, contribuem diretamente com o desequilíbrio da microbiota intestinal das aves de produção. Diante disso, faz-se necessário o conhecimento sobre o funcionamento de todo o ecossistema do trato gastrointestinal das aves de produção, pois, através de manejos e aditivos, podemos modular e influenciar positivamente essa microbiota intestinal, melhorando a absorção e o desempenho animal. Para tanto, essa revisão bibliográfica objetiva apresentar as principais características do sistema gastrointestinal das aves de produção, com ênfase na microbiota intestinal, bem como, na utilização de aditivos alimentares moduladores de microbiota intestinal.

\section{Metodologia}

O presente estudo trata-se de uma revisão narrativa acerca do Hábitats da microbiota intestinal e alguns aditivos equilibradores de microbiota em aves de produção. A revisão abrangeu, em sua maioria, artigos científicos, mas foram também utilizadas teses e dissertações presentes na base de dados do Scielo (Scientific Eletronic Library Online), Science Direct e Google Acadêmico. Descartou-se trabalhos sem resumo e que não abordavam a temática do estudo, assim como aqueles que apresentavam metodologias mal aplicadas ou suspeitas.

\section{Revisão Bibliográfica}

\subsection{Microbiota Intestinal das Aves de produção}

\subsubsection{Microbiota Residente e colonização do trato gastrointestinal}

A microbiota intestinal residente é o termo que diz respeito a população de microrganismos que compõe o trato gastrointestinal animal, e que correspondem a um conjunto de microrganismos (bactérias, protozoários, fungos e/ou leveduras) que vivem em equilíbrio neste segmento do hospedeiro, podendo ser comensais e/ou mutualísticas. Exercem papel fundamental na manutenção da saúde intestinal e influencia o desempenho das aves através da modulação do sistema imune, digestão de nutrientes e regulação da função intestinal (Khan et al., 2020).

Em sua grande maioria, os estudos de mapeamento da microbiota intestinal das aves foram estabelecidos com pesquisas realizadas em frango de corte de crescimento lento e rápido, sendo pouco as explorações com galinhas poedeiras. Apesar de serem da mesma espécie, as linhagens de aves poedeiras e frangos de corte possuem microbiota distinta por divergirem na fisiologia, metabolismo de nutrientes, demanda energética e longevidade (Khan et al., 2020). Entretanto, o microbioma central - filo Firmicutes e Proteobacteria - em ambas linhagens são comuns, variando a população de algumas 
espécies devido às particularidades da fisiologia da ave (Ocejo et al., 2019). Apesar dos estudos já realizados, ainda não foi atingido um mapeamento completo da microbiota das aves.

A colonização do trato gastrointestinal (TGI) das aves pode ocorrer antes ou após a eclosão dos ovos, isso vai depender de alguns fatores, como o manejo sanitário, higienização do incubatório e saúde das matrizes. Nesse aspecto, os animais podem entrar em contato com cepas bacterianas desde o desenvolvimento embrionário, contaminando o ovo antes da oviposição (transmissão vertical) ou após (transmissão horizontal) (Macari et al., 2014).

A transmissão vertical ocorre devido a presença de cepas bacterianas que sobrevivem tanto no ambiente da cloaca quanto do sêmen animal e por haver cepas patogênicas que conseguem atingir níveis sistêmicos, podendo alojar-se em órgãos como o baço, fígado, ovários e oviduto, levando inclusive a carga bacteriana para o interior dos ovos; como exemplo desta contaminação temos a Salmonella enterica (Gast et al., 2020). Essa infecção sistêmica se dá pela sobrevivência intracelular da bactéria nos macrófagos das aves, aderência à mucosa do trato reprodutivo e invasão de células da granulosa ovariana (Babu et al., 2016).

Por outro lado, a via horizontal necessita do contato direto dos ovos com o meio contaminado por microrganismos, que se proliferam na superfície da casca e no interior dos ovos por adentrarem através dos poros da casca (Mendes et al., 2014; Van Goor et al., 2020).

Após a eclosão, a ave já apresenta uma carga bacteriana, sendo esta provinda da mãe ou do ambiente (incubatório, aviário, entre outros) no qual o ovo foi exposto, esta microbiota consegue se desenvolver e amadurecer com a exposição contínua a rações, água, cama, insetos, poeira e tratadores, pois inicialmente as cepas são imaturas e apresentam baixa diversidade (Macari et al., 2014). A microbiota residente pode ser influenciada pelas vias de contaminação, o que torna cada ave diferente entre si.

A diversidade microbiana após a eclosão é representada por bactérias Gram-negativas, em particular da família Enterobacteriaceae, que inclui as principais cepas patogênicas, como Salmonella, Klebsiella, Proteus e E. coli (Ballou et al., 2016). Ainda na primeira semana, há uma mudança gradual para uma comunidade mais diversificada composta de bactérias Gram-positivas, resultando em uma proporção menor de Gram-negativas, no qual o trato digestivo é colonizado por cepas pertencentes a ordem Clostridiales, o que inclui os Clostridium (Ballou et al., 2016). Os Ruminococcus e Lactobacillus, também passam a colonizar o trato (Macari et al., 2014). Contudo, pode-se afirmar presença das espécies pertencentes a Clostridiales, Firmicutes, Proteobacterias, Enterococcus e Streptococcus (Ocejo et al., 2019).

A maturação da microbiota das aves ocorre após a primeira semana de vida, respectivamente, entre 14 à 28 dias de idade, período que ocorre grandes mudanças nas colônias bacterianas existentes no TGI, podendo este ser colonizado por novas cepas bacterianas ou até mesmo sofrer redução ou desaparecimentos de outras (Ballou et al., 2016). Neste cenário de maturação do TGI e da comunidade microbiana, as cepas que permanecem são as relacionadas a Lactobacillus, Clostridiales, e Proteobacterias, surgindo novas pertencentes à Eubacterium, Fusobacterium e Bacteroides. Só após esse período considera-se que a microbiota atingiu a maturidade (Ocejo et al., 2019) e sendo considerada estável só após 49 dias (Al-Khalaifah, 2018; Feitosa et al., 2020).

\subsubsection{Habitats e particularidades da Microbiota Residente}

O TGI das aves é composto por bico, inglúvio, proventrículo, ventrículo/moela, intestino delgado (duodeno, jejuno e íleo), intestino grosso (ceco, colón e cloaca) (Yadav e Jha, 2019). Em cada porção do trato há populações microbianas distintas devido as diferenças na funcionalidade, morfologia, interações metabólicas e microambiente de cada segmento (Macari et al., 2014). Em geral, as espécies microbianas comumente encontradas no trato das aves são as dos gêneros Lactobacillus sp., 
Bacteroides sp., Eubacterium sp., Clostridium sp., Escherichia coli, Streptococcus sp., Prevotella sp., Fusobacterium sp., Selenomonas sp., Megasphaera sp. e Bifidobacterium sp (Yadav e Jha, 2019).

Desde o inglúvio até a cloaca há colonização e proliferação de cepas que pertencem a microbiota residente. As regiões proximais por terem $\mathrm{pH}$ mais ácidos é normal que haja a predominância de cepas tolerantes a essas condições, como é o caso de bactérias ácido-láticas, como exemplo os Lactobacillus, que chegam a colonizar esses segmentos em até 100\%, decaindo a população ao longo do trato (Christofoli et al., 2020). No inglúvio, podemos encontrar a presença da cepa L. salivarius (Barros et al., 2009) e no estômago L. aviarius (Gong et al., 2007; Alexandrino et al., 2020).

Apesar dessa predominância nas regiões proximais do trato digestivo, as cepas ácido-láticas não apresentam tanta eficácia no inglúvio que apresenta um pH: 4,8; além do que, as aves tem ausência de mastigação, embora, ainda há indícios de pequena atividade fermentativa que chegam a hidrolisar o amido (Macari et al., 2014).

O proventrículo por possuir um pH entre 2,8 e 4,0; e por haver secreções de enzimas e ácidos, o ambiente torna-se propicio ao início da a atividade microbiana, contudo, a baixa permanência do bolo alimentar no segmento impede uma maior efetividade das bactérias (Alexandrino et al., 2020). Quanto ao ventrículo que possui pH entorno de 3,5 pode-se notar maior ação das enzimas microbianas devido a trituração das partículas, possibilitando assim um maior contato entre os fragmentos e as enzimas. Além desta atividade, há também degradação de proteínas, que é realizada através da ação sofrida das bactérias no suco gástrico, sendo estas aproveitadas nos segmentos posteriores, (Yadav e Jha, 2019).

O duodeno é um segmento localizado na porção inicial do ID (Fraga, 2013), é onde há maior variação de pH entorno de 6,0 à 6,5 devido a presença do quimo, resíduos de enzimas gástricas e a excreção de enzimas pancreáticas e entéricas e sais biliares. Essa troca de pH torna o meio inóspito para o desenvolvimento e proliferação de cepas no lúmen, entretanto, a camada espessa de muco que reveste as células do enterócito, possibilita a colonização de algumas cepas. Porém a comunidade e a diversidade microbiana são muito baixa neste segmento, havendo predominância apenas dos Lactobacillus e alguns Clostridiales e enterobactérias, por serem tolerantes ao pH levemente ácido (Christofoli et al., 2020).

O jejuno é caracterizado como o segmento localizado entre o duodeno e o íleo, nessa porção do ID há uma forte proliferação de comunidades microbianas devido ao tempo de maior permanência do bolo alimentar. Ao longo deste segmento o pH varia de 5,8 à 6,6; o que favorece as bactérias fermentadoras de ácido lático, Clostridiales e Bacteroidetes. Outras espécies pertencentes ao gênero Ruminococcus podem estar presente nesta porção do ID, por haver presença de carboidratos estruturais na dieta e por estes serem degradadores destas macromoléculas (Christofoli et al., 2020; Khan et al., 2020).

O íleo é a parte terminal do ID, está localizado entre o jejuno e a porção inicial do intestino grosso (IG), quando comparado com as porções anteriores, o mesmo possui um pH mais neutro, entorno de 6,3 à 7,2; está constantemente renovando a camada de muco devido a abundância de células caliciformes, torna o meio mais propício ao desenvolvimento/colonização de microrganismos no lúmen assim como as aderidas ao enterócito. Ainda assim, a predominância das cepas é do gênero Lactobacillus e enterobactérias (Christofoli et al., 2020).

O intestino grosso das aves se diferencia dos demais não-ruminantes por ter a presença de cecos duplos e funcionarem como câmara de fermentação de carboidratos estruturais, e por ser um ambiente anaeróbio, o que o torna propício a proliferação de microrganismos produtores de metabólitos essenciais (ácidos graxos de cadeia curta, vitaminas, hexoses, alguns aminoácidos, entre outros) para a manutenção da microbiota assim como dos enterócitos (Christofoli et al., 2020; Khan et al., 2020).

É no ceco que possui $\mathrm{pH}$ entorno de 6,3; onde se concentra a maior diversidade microbiana do trato gastrointestinal, esse segmento destaca-se como sendo o principal foco dos estudos por permitir a colonização e desenvolvimento de cepas patogênicas, como Clostridium perfringens. Os gêneros predominantes neste habitat são Ruminococcus, Faecalibacterium, Eubacterium e Bacteroides (Feitosa et al., 2020). 
Além de todas as particularidades envolvendo o trato gastrointestinal, torna-se de grande importância o conhecimento sobre as ligações estabelecidas entre hospedeiro e a microbiota, assim como a compreensão sobre os microhabitats formados nessa grande estrutura. A microbiota pode ser estabelecida no lúmen intestinal assim como aderidas ao enterócito, o que determina a colonização e permanência neste habitat é existência de fímbrias na composição estrutural do microrganismo (Macari et al., 2014).

A ausência de fímbrias nas cepas de Enterococcus e Bacillus permite que estes se proliferem no lúmen entrando em maior contato com as partículas de alimento disponibilizando nutrientes para as cepas aderidas ao enterócito, como os Lactobacillus que se ligam as estruturas glicoproteicas do glicocálix formando uma barreira natural contra patógenos. Esta ligação específica ao tecido, chamada de chave-fechadura, favorece cepas benéficas (Macari et al., 2014).

A camada de muco presente no ID, denominada mucina consiste em duas camadas sendo uma externa solta no qual os microrganismos podem colonizar e outra camada interna compacta que repele a maioria das bactérias impedindo a colonização, servindo como a primeira linha de defesa (Pan e Yu, 2013).

Ambas as camadas são formadas por uma matriz proteica e rica em oligossacarídeos, fontes essenciais de proteína e carboidrato para a microbiota (Macari et al., 2014). A microbiota aderida a esta estrutura também se nutre dos nutrientes resultantes da digestão luminal, que ficam concentrados no muco para posterior absorção (Khan et al., 2020).

Esta simbiose favorece a formação de barreira natural contra microrganismos oportunistas, assim como estimula a produção de muco que também é uma barreira. A aderência de microrganismos comensais causam diminuta degradação celular das vilosidades, entretanto isto estimula a imunidade local não específica, levando a produção de imunoglobulinas que agem na mucosa intestinal, que por sua vez controlam a proliferação microbiana excessiva (Pan e Yu, 2013).

Em geral, o desenvolvimento da microbiota é um processo contínuo de sucessão de populações microbianas que depende da idade e do desenvolvimento do TGI, no qual algumas famílias e espécies são substituídas por outras à medida que as aves se desenvolvem (Ocejo et al., 2019).

\subsection{Aditivos Equilibradores de Microbiota Intestinal}

Aditivos equilibradores da microbiota intestinal segundo a Instrução Normativa 13 de 30 de novembro de 2004 (alterada pela Instrução Normativa no 44/15) emitida pelo Ministério da Agricultura, Pecuária e abastecimento (MAPA), são microrganismos que formam colônias ou outras substâncias definidas quimicamente que têm um efeito positivo sobre a microbiota do trato digestório (BRASIL, 2015).

Os primeiros relatos do uso de aditivos equilibradores de microbiota foram em 1948 nos estudos de identificação e isolamento da vitamina $B_{12}$ em culturas fúngicas, no qual foi demonstrado que a massa micelar obtida nas culturas produziam antibióticos, que atuavam como melhorador de desempenho (Gonzales et al., 2012). A descoberta dos antibióticos transformou o mundo ao tornar tratáveis doenças e permitir o uso em doses baixas para prevenir infecções.

Após o achado dos antibióticos como moduladores da microbiota intestinal, surgiram novas descobertas relacionadas a substâncias com função de equilibradores de microbiota, as quais segundo a IN nº 44/15/MAPA são os probióticos, prebióticos, simbióticos e acidificantes (ácidos orgânicos e inorgânicos) (BRASIL, 2015).

\subsubsection{Antibióticos como Melhoradores do Desempenho Animal}

Os antibióticos são substâncias utilizadas para tratar ou prevenir infecções causadas por bactérias patogênicas e outros microorganismos, são considerados um dos desenvolvimentos mais importantes da medicina moderna. A palavra 'antibiótico' é derivada do termo grego 'biotikos' podendo ser traduzida literalmente como 'contra a vida' (Conly e Johnston, 2004). 
Ao longo dos anos os antibióticos ganharam algumas definições, segundo Guimarães et al. (2010), os antibióticos são compostos naturais ou sintéticos capazes de inibir o crescimento ou causar a morte de fungos ou bactérias. Para Gonzales et al. (2012), os antibióticos (AB) são substâncias sintetizadas por microrganismos ou produzidas em laboratórios a partir de um princípio ativo sintetizados por fungos ou bactérias e que têm ação antimicrobiana. Uma definição mais atual sobre o termo antibiótico e regida pelo Compêndio Brasileiro de Alimentação Animal (2017), sendo substâncias administradas em produtos destinados à alimentação animal com a finalidade de melhorar a taxa de crescimento e/ou eficiência da conversão alimentar (Reis e Vieites, 2019).

O termo antibiótico foi utilizado pela primeira vez em 1945 por Wasksman, 49 anos após a primeira evidência de que substâncias produzidas por fungos tinham a capacidade de inibir o crescimento bacteriano. No início da década de 40, no século 20, os antibióticos já tinham sido isolados e identificados, tendo assim indicações para o tratamento de doenças em humanos e posteriormente em animais (Gonzales et al., 2012).

O sucesso da alimentação animal com os antibióticos foi descoberto na década de 1940, durante os estudos de identificação e isolamento da vitamina $B_{12}$ em culturas fúngicas, onde se observou que pintainhos da linhagem New Hampshire, quando alimentados com micélios de Streptomyces aureofaciens, contendo resíduos do antibiótico clorotetraciclina, melhoraram seus desempenhos de crescimento (Stokstad et al.,1949; Jones e Ricke, 2003; Reis e Vieites, 2019).

A partir da década de 1950, além de serem utilizados para tratar as infecções, os antibióticos também foram utilizados como mecanismos para estabelecer e manter uma qualidade no ambiente intestinal dos animais de produção, administrados continuamente na dieta em concentrações menores do que as administradas como profilaxia ou terapia (Gonzales et al., 2012).

Os efeitos sobre a melhoria do desempenho zootécnico decorrentes ao uso dos antibióticos, se dá pela ação dos mesmos sobre a microbiota do trato gastrointestinal, diminuindo as competições por nutrientes e reduzindo a produção de metabólitos que deprimam o crescimento animal. Além disso, tais substâncias podem promover uma redução no tamanho e peso do trato digestório, tornando mais finas as vilosidades e paredes intestinais, em decorrência da redução de ácidos graxos de cadeia curta e poliaminas produzidos pela fermentação microbiana, proporcionando maior produtividade, maior crescimento, melhor saúde e resistências as doenças condicionando um menor índice de mortalidade animal (Gonzales et al., 2012).

As evidências do uso de antibióticos em subdosagens como promotor de crescimento foram bem vistas, de tal forma que em 1951 o Food and Drug Administration (FDA) dos EUA aprovaram o uso dos aditivos nas rações animais sem prescrição veterinária (Hume, 2011; Gonzales et al., 2012). Na década de 1950 e 1960, cada Estado Europeu aprovou também suas próprias regulamentações nacionais sobre o uso de antibióticos nas rações animais (Reis e Vieites, 2019). Esse uso de antibióticos nas rações animais, permitiu a realização de criações em grandes densidades, aumentando a produtividade e melhorando as taxas de crescimento em 4 a 8\% e a conversão alimentar de 2 a 5\% (Ajuwon, 2015; Reis e Vieites, 2019).

Desde então a avicultura industrial se promoveu com o uso constante de aditivos em dietas, por serem visíveis as melhorias no desempenho e na saúde do plantel. Entretanto, o uso constante e intenso dos antibióticos desencadeou a seleção de linhas bacterianas resistentes.

\subsubsection{Resistência Bacteriana ao Uso dos Antibióticos}

Nas últimas décadas, foram documentados aumentos na incidência de infecções humanas por bactérias resistentes a antibióticos (Threlfall et al., 2000; Silbergeld et al., 2008). O número crescente de incidências de resistência aos antibióticos foi hipotetizado como diretamente relacionado ao uso excessivo de antibióticos necessários para tratamentos profiláticos médicos em humanos e terapêuticos na produção de alimentos para animais (Hume, 2011). 
Os primeiros indícios de uma possível resistência bacteriana aos antibióticos, foi relatada pelo pesquisador Alexander Fleming (médico bacteriologista escocês que descobriu a penicilina, em 1928) que durante seu discurso em homenagem ao recebimento do prêmio Nobel de Fisiologia e Medicina, em 1945, alertou sobre a possibilidade de doses subterapêuticas (subdosagens) gerarem microrganismos resistentes (Reis e Vieites, 2019).

Em 1997 a Organização Mundial de Saúde (WHO), declarou que a resistência microbiana a antibióticos ocorre devido ao uso inadequado dos mesmos (interrupção do medicamento antes do tempo preconizado pelo médico, falta de acompanhamento ou mesmo do retorno do paciente ao médico e automedicação).

Cheng et al. (2016), alegou que a resistência microbiana aos antibióticos é um processo que ocorre naturalmente, porém pode ser acelerado com a exposição ao uso excessivo destes. A resistência dá-se quando as cepas alvo se mutam e não respondem aos princípios ativos do medicamento que se tornam ineficazes. Além disso, o processo também pode ocorrer através da reprodução (transformação, transdução ou conjugação) onde a bactéria transfere seu DNA para um plasmídeo, posteriormente o mesmo é transferindo para o genoma de outra bactéria condicionando a propagação do gene resistente.

Deste modo, a resistência bacteriana se tornou uma problemática na saúde animal e humana, por serem administrados em ambos, medicamentos com mesmos princípios ativos. A contaminação de produtos de origem animal - carne, ovos, esterco - por resíduos dos antimicrobianos levaram aos órgãos mundiais (WHO, 1997; UE, 2006 - citado por Castanon, 2007) e nacional (BRASIL, 2020) a elaborarem planos e normativas vetando a utilização de alguns antimicrobianos (Tabela 1) em dosagens subterapêuticas, pois o consumo destes produtos a longo prazo poderia levar a resistência bacteriana em humanos.

Tabela 1. Antimicrobianos proibidos como melhoradores de desempenho e alguns aditivos equilibradores de microbiota intestinal aprovados no uso na alimentação animal no Brasil

\begin{tabular}{lc}
\hline & PROIBIDOS \\
\hline Aditivos & Instrução Normativa / Decreto / Lei \\
\hline Avoparcina & Of. Circ. DFPA no 047/1998 \\
Arsenicais e antimoniais & Portaria no 31, 29/01/2002 \\
Cloranfenicol e Nitrofuranos & IN no 09, 27/06/2003 \\
Olaquindox & IN no 11, 24/11/2004 \\
Carbadox & IN no 35, 14/11/2005 \\
Violeta Genciana & IN no 34, 13/09/2007 \\
Anfenicóis, tetraciclinas, beta lactâmicos & IN no 26, 9/07/2009 (revoga Portaria 193/1998) \\
(benzilpenicilâmicos e cefalosporinas), & \\
quinolonas e sulfonamidas sistêmicas & IN no 14, 17/05/2012 \\
Espiramicina e eritromicina & IN no 45, de 22/11/2016 \\
Colistina & IN no 01, de 13/01/2020 \\
Tilosina, Lincomicina e Tiamulina & Classificação \\
\hline & Melhorador de desempenho \\
\hline Nome & Melhorador de desempenho \\
\hline Avilamicina & Melhorador de desempenho \\
Bacitracina de Zinco & Probiótico \\
Extrato de casca de carvalho & Probiótico \\
Bacillus licheniformis & Probiótico \\
Bifidobacterium bifidum & Prebiótico \\
Enterococcus faecium & APDOS \\
Extrato de Hemicelulose & .
\end{tabular}

Fonte: Adaptado, (MAPA, 2009; 2012; 2016; 2020). 
Apesar das proibições dos antibióticos pelos órgãos mundiais (WHO, UE, FDA) ligados à área de saúde, no Brasil segundo a normativa de número 01 de 13 de janeiro de 2020 imposta pelo órgão Ministério da Agricultura, Pecuária e Abastecimento - MAPA, o antibiótico bacitracina de zinco ainda é usual em dosagens subterapêuticas.

\subsubsection{Bacitracina de Zinco}

A bacitracina (Figura 1) foi originalmente descoberta em 1945 por Johnson e colaboradores na University Columbia em Nova York nos estados unidos (EUA) (Harwood et al., 2018; Carramaschi, 2019). Classificado como um antibiótico polipeptídio não ribossomal de amplo espectro produzidos por cepas de Bacillus licheniformis e B. subtilis, cuja composição e estrutura são complexas e atuam sobre as bactérias Gram-positivas: estreptococos, estafilococos, corinebactérias e clostrídios (Pavli e Kmetec, 2006; O’Donnell et al., 2015). Existe três subgrupos de bacitracina: A, B e C. O subgrupo A é o principal constituinte das preparações comerciais (O'Donnell et al., 2015).

Figura 1. Formula molecular da bacitracina de zinco.

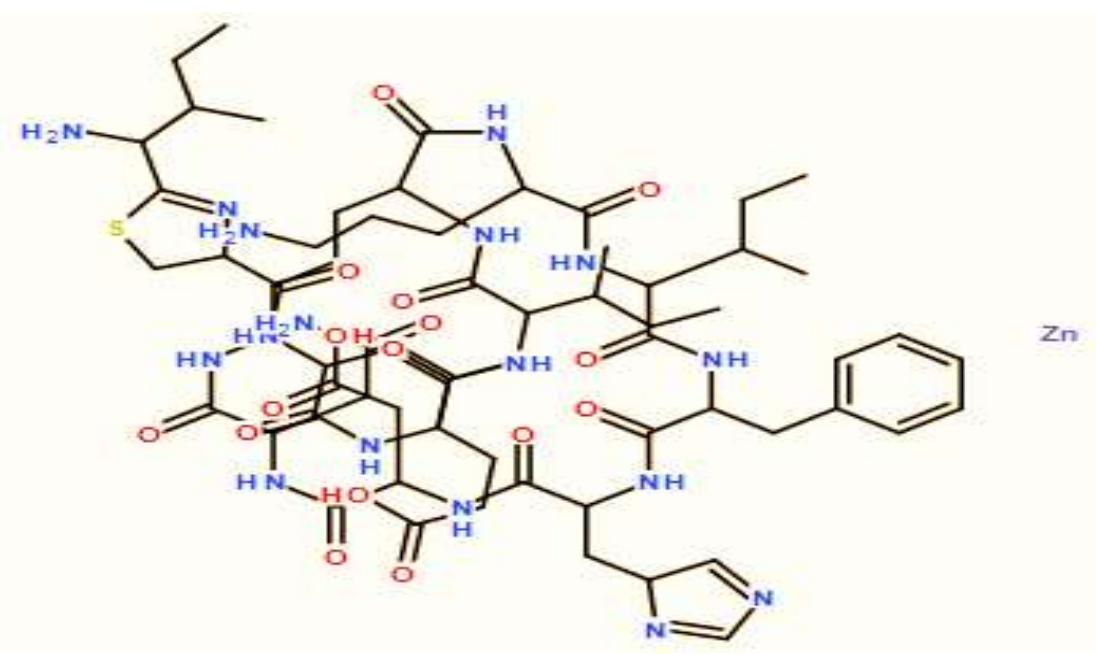

Fonte: labeyond.com/pt/Bacitracin.html

A bacitracina contém um anel tiazolina e cadeias laterais de peptídeos. Atuam na inibição do crescimento bacteriano de forma a impedir a desfosforilação de $\mathrm{C}_{55}$-undecaprenyl pirofosfato (Bactoprenol) um intermediário na biossíntese do peptidoglicano, principal componente de parede celular bacteriana (Siewert e Strominger, 1967; Harwood et al., 2018 ), na ausência do carreador monofosforilado, a síntese da subunidade do peptidoglicano para, com isso à uma atrofia sobre a parede celular da bactéria, impedindo seu desenvolvimento.

A biossíntese dos peptidoglicanos ocorre em três estágios, (1) biossíntese dos precursores de nucleotídeos da uridina, (2) utilização desses precursores para formar fitas lineares de peptidoglicano, e (3) reticulação dos fios lineares. Cada estágios é inibido especificamente por diferentes antibióticos. Ristocetina, vancomicina e bacitracina são todos iknibidores do segundo estágio (Siewert e Strominger, 1967).

Recentemente Crisol-Martínez et al. (2017), comprovou em sua pesquisa que a bacitracina ainda é eficaz sobre o desempenho e sobre a microbiota cecal de frangos de corte. Contudo, a tendência mundial é banir a utilização de antibióticos em dietas dos animais para promover crescimento.

Entretanto, os animais continuam submetidos a ambientes adensados que favorecem a proliferação de patógenos, doenças e estresse que deprimem o sistema imune, tornando os animais mais vulneráveis, sendo impossível a isenção de 
compostos na dieta que aprimorem a microbiota intestinal (Toledo et al., 2007), e consequentemente a digestibilidade e absorção dos nutrientes da ração (Matur et al., 2010; Feitosa et al., 2020).

Por isso, há busca por aditivos equilibradores da microbiota alternativos e comensais, que não causem resistência bacteriana, tem sido constante. Pesquisas neste âmbito demonstraram que alternativas como prebióticos, probióticos e simbióticos tem sido promissora.

Akbaryan et al. (2019), ao comparar os efeitos dos prebióticos - amido resistente e frutooligossacarídeos - com a bacitracina de zinco, sobre a microbiota cecal, morfologia intestinal e títulos de anticorpo contra o vírus da doença de Newcastle em frangos de corte, constatou que as aves submetidas às dietas contendo prebióticos apresentaram melhores índices quando comparadas as aves que consumiram a bacitracina de zinco.

Thema et al. (2019), constatou que aditivos alternativos (probiótico - Bacillus subtilis), ácidos orgânicos, protease e minerais quelados) e suas combinações podem substituir a bacitracina de zinco em dietas para frangos de corte, por não promoverem a resistência microbiana e contribuírem para o desenvolvimento produtivo da ave.

\subsubsection{Prebiótico}

\subsubsection{Histórico, Definição e Fontes}

O termo prebiótico foi utilizado pela primeira vez em 1995 por Gibson e Roberfroid, onde classificaram como sendo um ingrediente alimentar não digerível que afeta beneficamente o hospedeiro ao estimular seletivamente o crescimento e/ou a atividade de uma ou de um número limitado de bactérias no cólon e, assim, melhorando a saúde do hospedeiro.

Ainda segundo os mesmos autores, para que um ingrediente seja considerado um prebiótico ele deve apresentar algumas características: não ser hidrolisado nem absorvido na parte superior do trato gastrointestinal; ser um substrato seletivo para uma ou um número limitado de bactérias benéficas comensais ao cólon que são estimuladas a crescer e/ou são ativadas metabolicamente; ser capaz de alterar a flora das colônias em favor de uma composição mais saudável, e induzir efeitos luminais ou sistêmicos benéficos à saúde do hospedeiro.

Ao longo dos anos, a classificação dos prebióticos sofreu algumas modificações. Atualmente a definição melhor aceita foi descrita por Bindels et al. (2015). Os autores definem como sendo compostos não digeríveis que, por meio de sua metabolização por micro-organismos no intestino, modulam a composição e/ou atividade da microbiota intestinal, conferindo efeito fisiológico benéfico ao hospedeiro.

Os prebióticos são essencialmente formados por carboidratos com ramificações e tamanhos diferenciados, podendo ser monossacarídeos, dissacarídeos, oligossacarídeos e polissacarídeos (Raizel et al., 2011). A sua extração pode vir de diversas fontes alimentares como alguns cereais, tubérculos e raízes, assim como da parede de micro-organismos, tais como glucanos e mananos quando extraídos da parede celular da levedura Saccharomyces cerevisiae (Raizel et al., 2011; Lemos et al., 2016), mas, em geral, a maior parte da extração é de fonte vegetal. Dentre os prebióticos mais usuais estão os frutooligossacarídeos (FOS), mananoligossacarídeos (MOS), $\beta$-glucanos e os xilooligossacarídeos (XOS).

Os frutooligossacarídeos (FOS) e a inulina, sua versão de cadeia mais longa (de 3 a 60 monômeros), estão entre os prebióticos mais estudados em humanos e animais. Os FOS são carboidratos de cadeia curta e não digeríveis, formados por polímeros lineares naturais de 2 até 10 monoméricos, onde de 2 a 9 unidades de frutosil se unem através de ligações glicosídicas $\beta$ - (2-1) e $\alpha$ - (1-2), terminadas por um resíduo de glicose (Pourabedin e Zhao, 2015; Shang et al., 2018; Macedo et al., 2020) e obtidos através da hidrólise da inulina (Raizel et al., 2011). Normalmente os FOS são encontrados nas formas de 1kestose (GF2), nistose (GF3) e frutofuranosil nistose (GF4) (Macedo et al., 2020).

Essa ligação $\beta$-glicosídica presente nos frutanos confere resistência à quebra da molécula por parte das aves pela ausência de enzimas digestivas específicas. Desse modo, apenas grupos seletos de bactérias benéficas, como exemplo 
Bifidobacterium e Lactobacillus formadoras de ácido láctico, conseguem digerir este substrato e se beneficiar, ocasionando aumento da população. Com o aumento da população destas cepas, consequentemente haverá maior produção de ácido lático, tornando o meio luminal levemente ácido deixando o ambiente inóspito para a proliferação de bactérias patogênicas, como Clostridium pefrigens e E. coli em aves (Ricke, 2015).

Outro grupo do prebiótico compreende os mananoligossacarídeos (MOS), que são oligômeros à base de manose ligados entre si por ligações glicosídicas $\beta$ - $(1,4)$, normalmente encontrados em determinadas plantas como o feijão ou na porção manoproteína da parede celular da Saccharomyces cerevisiae, cujos principais componentes, mananos e $\beta$-glucanas (manoproteínas), são conhecidos por induzir a ativação do sistema imunológico dos animais (Pourabedin e Zhao, 2015; Diaz et al., 2018).

Já os $\beta$-glucanos são polissacarídeos de cadeia longa, compostos de monômeros de D-glicose unidos entre si por ligações glicosídicas $\beta$ - $(1,3)$ e $\beta$ - $(1,6)$, derivados de leveduras ou de paredes celulares de fungos (Teng e Kim, 2018). Por terem a composição formada por ligações beta, essa classe de prebiótico se ligam a receptores específicos de macrófagos que reconhecem os açúcares específicos encontrados em glicoproteínas da superfície epitelial, estimulando a fagocitose pelos macrófagos e a produção de citocina que ativa a produção de linfócitos, aumentando consequentemente a resposta imune inata e adquirida (Świątkiewicz et al., 2014).

Nas aves, por não possuírem enzimas responsáveis pela hidrólise das ligações deste composto, acredita-se que este oligossacarídeo alcance o trato gastrointestinal inferior sem ser digerido. Ao atingir a nível de intestino, os carboidratos contendo manose se ligam às lectinas patogênicas e impedem a sua fixação ao enterócito, desse modo, há uma diminuição da população patogênica no trato (Teng e Kim, 2018).

Outra fonte prebiótica são os xiloligossacarídeos (XOS), que são formados por unidades de D-xilopiranosídeo ligados entre si por ligação $\beta$ - $(1,4)$. Sua produção se dá pela degradação hidrolítica parcial de materiais lignocelulósicos, como os cereais. A sua estrutura formada por ligações glicosídicas entre os monômeros de xilose faz com que atinja o trato intestinal, principalmente o ceco, pois é onde ocorre maior fermentação sem ser degradado, uma vez que as aves não possuem enzimas específicas para a quebra das ligações (Pourabedin e Zhao, 2015).

\subsubsection{Mecanismo de Ação}

Em geral, os prebióticos, quando inseridos nas dietas das aves, atuam de diferentes formas dentro dos segmentos do trato digestivo, obtendo maior atividade na parte inferior do trato (ceco) por haver maior população e diversidade microbiana. Os mecanismos de ação no organismo do animal variam de acordo com a fonte utilizada (MOS, FOS, $\beta$-glucanos, entre outros).

Os mecanismos de ação dos prebióticos mais relatados na literatura são como substrato para cepas benéficas, barreiras físicas no intestino e estimuladores do sistema imune. Os prebióticos, quando fornecidos como substratos para espécies microbianas benéficas, geram metabólitos como derivados de ácidos biliares, vitaminas e ácidos orgânicos - ácidos graxos de cadeia ramificada e ácidos graxos de cadeia curta (AGCC), que são absorvidos pelo animal e algumas substâncias antibacterianas, como a bacteriocina que atua sobre cepas patogênicas, alterando a população da microbiota residente (Bindels et al., 2015; Teng e Kim, 2018).

Os ácidos orgânicos provindos da degradação dos prebióticos alteram o pH intestinal, deixando o lúmen levemente ácido, tornando o meio inóspito para determinadas cepas patogênicas, como os gêneros Salmonella sp e E. coli (Lan et al., 2017). Essa alteração de pH também estimula a produção de enzimas pancreáticas o que acarreta ao maior contato da ingesta com as enzimas melhorando a digestibilidade dos nutrientes (Ricke et al., 2020). 
Os metabólitos produzidos são aproveitados pelo animal de forma eficiente, acarretando a otimização no desempenho produtivo. Esses metabólitos gerados a partir da digestão dos substratos são aproveitados de forma mútua pelo animal, além de apresentar atividade antimicrobiana, melhora a integridade das células do enterócito e regula a população microbiana do trato gastrointestinal (Ricke et al., 2020).

Como barreira física, os prebióticos possuem ligações glicosídicas que se aderem à mucosa intestinal, formando uma espécie de barreira, impedindo a adesão de bactérias, fungos e protozoários patogênicos à parede das células do enterócito, dessa forma, os patógenos se ligam ao prebiótico e são eliminados do trato digestivo através das fezes/excreta. Em resposta à ligação prebiótico-enterócito, há estímulo à produção de mucina pelas células caliciformes do epitélio luminal, formando uma barreira natural de muco, dificultando a aderência de patógenos (Forte et al., 2018).

Essa adesão do prebiótico à mucosa também gera resposta imunológica, onde as células sentinelas como as dendríticas, macrófagos e os mastócitos, ao realizarem o reconhecimento de padrões moleculares associados a patógenos, capturam à molécula, processam e apresentam antígenos para os linfócitos (Antonialli, 2013; Teng e Kim, 2018). Este reconhecimento induz a maturação da célula dendrítica, um processo essencial para ativar os linfócitos T e B produzidos pelos órgãos timo e bursa de fabricius nas aves, respectivamente (Antonialli, 2013).

Outra forma de atuação do prebióticos é como antígenos não patogênicos. Eles, por serem reconhecidos pelos receptores de células imunes, agem também como adjuvantes de vacinas, aumentando os títulos de anticorpos (Teng e Kim, 2018).

Logo, os prebióticos apresentam vários efeitos benéficos fisiológicos, metabólicos e imunológicos, conferindo ao animal melhoria na microbiota residente, na integridade dos enterócitos e consequentemente no desempenho produtivo.

Diversas pesquisas vêm demonstrando os benefícios mútuos destes substratos na alimentação de aves, quando inseridos a sós ou em conjunto com outros grupos prebióticos (Al-Khalaifa et al., 2019; Froebel et al., 2019; Kridtayopas et al., 2019; Rehman et al., 2020; Ricke et al., 2020).

\subsubsection{Probiótico}

\subsubsection{Histórico e Definição}

O termo probiótico é derivado do latim (pro) e grego (bios), que significa "para a vida" (Gogineni, 2013; Sidjabat e Blackall, 2020), sendo o antônimo de antibiótico, que significa "contra-vida" (Coppola; Turnes, 2004; Murarolli, 2008).

Os primeiros relatos demonstrando a influência dos micro-organismos sobre a saúde, foram realizados por Metchnikoff em 1907, onde o pesquisador observou uma maior longevidade em camponeses búlgaros que consumiam leite fermentado por bactérias produtoras de ácido láctico (um exemplo de probiótico - Lactobacillus acidophilus), que atribuía proteção contra infecções gastrintestinais e redução do câncer de cólon pela sua ingestão (Silva e Filho, 2000; Maity e Misra, 2009).

O termo probiótico ganhou várias definições ao longo dos anos, contudo, a definição mais amplamente aceita sobre os probióticos, é descrita pelos órgãos de pesquisa conjunta FAO e WHO sendo "micro-organismos vivos que, quando administrados em quantidades adequadas, conferem um benefício à saúde do hospedeiro" (FAO, 2016).

Os probióticos são constituídos por várias espécies de bactérias benéficas, fungos ou leveduras que, além de promover o crescimento animal, também são capazes de eliminar bactérias patogênicas como Salmonella typhimurium, Staphylococcus aureus, Escherichia coli, Clostridium perfringens (Iannitti e Palmieri, 2010; Alagawany et al., 2018). Podem ser fornecidos como um suplemento alimentar microbiano vivo na dieta ou na água das aves e também podem ser administrados ao embrião em desenvolvimento usando tecnologia de alimentação in ovo (Pender et al., 2016; Jha et al., 2020). 


\subsubsection{Mecanismo de Ação e Fontes}

Dentre os mecanismos de ação dos probióticos, destacam-se a inibição de patógenos pela produção substâncias antibacterianas, como as bacteriocinas, ácidos orgânicos, peróxido de hidrogênio e defensinas, inibição competitiva pelo bloqueio de adesão das bactérias patogênicas aos locais de ligação epitelial intestinal, modulação das respostas imune do hospedeiro, regeneração da mucosa intestinal e secreção de enzimas digestivas (Tiwari et al., 2012; Alagawany et al., 2018).

Os probióticos também podem atuar na regulação de produção de citocinas anti e pró inflamatórias (Roselli et al., 2005; Alagawany et al., 2018), estimulando a produção de anticorpos, aumentando a atividade das células naturais de killer e macrófagos, também podendo estimular as funções de barreira epitelial e regular a produção de muco, motilidade intestinal, bem como, o baixo pH, que facilita a absorção de proteínas e minerais, como cobre, cálcio, ferro, manganês e magnésio (Raghuwanshi et al., 2015; Alagawany et al., 2018).

Cada probiótico possui mecanismos de ação distintos, o que lhes confere uma eficácia protetora variável. Nesse contexto, muitos produtos comerciais utilizam um mix de cepas probióticas que agem em diferentes locais e modos, criando efeitos sinérgicos benéficos ao animal.

Para que se utilize uma bactéria como probiótico, deve-se seguir alguns critérios básicos, como tolerância a condições gastrointestinais, capacidade em suportar pH baixo e altas concentrações de ácidos biliares (FAO, 2016), exclusão competitiva de patógenos e capacidade de aderir à mucosa gastrointestinal (Klaenhammer e Kullen, 1999; Gadde et al., 2017; Jha et al., 2020). Além disso, os probióticos são selecionados com base em sua sobrevivência na fabricação, armazenamento, transporte, processos de aplicação, capacidade de manter a viabilidade e suas características desejáveis (FAO, 2016; Jha et al., 2020).

Existe vários tipos de micro-organismos com potencial para serem utilizados como fonte probiótica, porém, os tipos mais comuns são as bactérias ácido lácticas e as bifidobactérias, embora outras bactérias e certas leveduras também sejam utilizadas (Didari et al., 2014). As cepas benéficas de caráter probiótico mais comumente usadas na nutrição animal são as do gênero Lactobacillus spp, Bifidobacterium spp, Enterococcus spp, Bacillus subtilis e Saccharomyces spp. Podendo estas serem extraídas de produtos fermentados, não fermentados e do corpo animal/ humano (leite, conteúdo intestinal, fezes) (Soccol et al., 2010; Alagawany et al., 2018).

\subsubsection{Simbiótico}

O termo simbiótico foi formado a partir do prefixo grego "syn", que significa "junto", e do sufixo "biótico", que significa "pertencente à vida" (Swanson et al., 2020). E foi descrito pela primeira vez em 1995 por Gibson e Roberfroid, definido como "uma mistura de probióticos e prebióticos que afeta beneficamente o hospedeiro, melhorando a sobrevivência e implantação de suplementos alimentares microbianos vivos no trato GI, estimulando seletivamente o crescimento e / ou ativação do metabolismo de uma ou de um número limitado de bactérias promotoras da saúde, melhorando assim o bem-estar do hospedeiro" (Gibson e Roberfroid, 1995).

Posteriormente, estudos sugeriram novos conceitos sobre o termo "Simbiótico", na qual, o termo mais bem aceito foi proposto pela Associação Científica Internacional para Probióticos e Prebióticos (ISAPP) como sendo "uma mistura que compreende micro-organismos vivos e substratos utilizados seletivamente por micro-organismos hospedeiros benéficos que confere um benefício à saúde do hospedeiro" (Swanson et al., 2020).

De modo geral, o mecanismo de ação do simbiótico sobre a saúde animal está ligado ao fato de seus componentes favorecerem o equilíbrio sobre a microbiota intestinal através da redução do $\mathrm{pH}$ luminal, tornando o meio propício ao crescimento de cepas bacterianas benéficas que estimularão a produção de bacteriocinas que ajudam a inibir o crescimento de bactérias patogênicas (Alavi et al., 2012) e enzimas pancreáticas para otimizar o aproveitamento dos nutrientes provindos da dieta, favorecendo o desempenho animal (Kuritza et al., 2014; Al-Khalaifah, 2018; Forte et al., 2018). 
Vários são os estudos demonstrando os efeitos positivos dos simbióticos na alimentação animal. Abdel-Wareth et al. (2019), analisando os efeitos de um aditivo simbiótico a base de Enterococuus faecium, Lactobacillus reuteri, Pediococcus acidilactici, Bifidobacterium animalis (probióticos) e Frutooligossacarídeo (prebiótico), na dieta de frangos de corte em condições climáticas quente, indicaram os efeitos positivos sobre o desempenho produtivo, qualidade da carne, redução dos níveis de amônia das excretas, bem como a redução dos níveis de bactérias patogênicas no animal.

Jiang et al. (2019), estudando o efeito de um simbiótico à base de Pediococcus acidilactici, Bifidobacterium animalis, Enterococcus faecium, Lactobacillus reuteris (probióticos) $e$ fruto-oligossacarídeos (Prebiótico) nas concentrações de (0,5 e $1,0 \mathrm{~g} / \mathrm{kg}$ ), em frangos de corte Ross 708 submetidos a estresse térmico cíclico (HS), apontaram que, sob condições de HS, ambos os grupos alimentados com simbiótico tinham níveis mais baixos de expressões de proteína de choque térmico (HSP70), e que o nível 1,0 g/kg ofereceu maior altura de vilosidades no duodeno e maior relação vilosidade e profundidade de cripta, demonstrando, assim, que o aditivo simbiótico utilizado pode ser uma estratégia para melhorar a saúde e bem-estar de aves quando expostas a altas temperaturas.

Kridtayopas et al. (2019) investigaram o efeito de um prebiótico (0,1\%) a base de mananoligossacarídeo (MOS) e um aditivo simbiótico (0,1\%) a base de Bacillus subtilis e Bacillus licheniformis (probiótico) e MOS (prebiótico) no desempenho de crescimento e população bacteriana em condições de alta densidade de estocagem (HSD) em frangos de corte Arbor Acres, onde concluíram que o uso do aditivo simbiótico ofereceu maiores benefícios aos animais quando comparados apenas a um de seus constituintes - prebióticos, isso devido ao mecanismo de ação conjunto dos componentes do simbiótico.

\section{Considerações Finais}

A microbiota intestinal das aves de produção é sem dúvida protagonista na melhora do desempenho animal. Para tanto, é necessário estar sempre se aprofundando nos estudos sobre a atuação dessa microbiota no ambiente intestinal, para então potencializar sua atividade através dos aditivos ideais, sem que haja prejuízo nutricional ao seu hospedeiro. A fisiologia animal colabora distribuindo em todo o trato gastrointestinal os microrganismos com funções específicas, esses agentes podem atuar conforme suas especificidades, promovendo melhora nutricional e defesa para as aves.

\section{Referências}

Abdel-Wareth, A. A. A., Hammad, S., Khalaphallah, R., Salem, W. M., \& Lohakare, J. (2019). Synbiotic as eco-friendly feed additive in diets of chickens under hot climatic conditions. Poultry Science, 98(10), 4575-4583. https://doi.org/10.3382/ps/pez115

Ajuwon, K. M. (2016). Toward a better understanding of mechanisms of probiotics and prebiotics action in poultry species. Journal of Applied Poultry Research, 25(2), 277-283. https://doi.org/10.3382/japr/pfv074

Akbaryan, M., Mahdavi, A., Jebelli-Javan, A., Staji, H., \& Darabighane, B. (2019). A comparison of the effects of resistant starch, fructooligosaccharide, and zinc bacitracin on cecal short-chain fatty acids, cecal microflora, intestinal morphology, and antibody titer against Newcastle disease virus in broilers. Comparative Clinical Pathology, 28(3), 661-667. https://doi.org/10.1007/s00580-019-02936-9

Al-Khalaifa, H., Al-Nasser, A., Al-Surayee, T., Al-Kandari, S., Al-Enzi, N., Al-Sharrah, T., Ragheb, G., Al-Qalaf, S., \& Mohammed, A. (2019). Effect of dietary probiotics and prebiotics on the performance of broiler chickens. Poultry Science, 98(10), 4465-4479. https://doi.org/10.3382/ps/pez282

Al-Khalaifah, H. S. (2018). Benefits of probiotics and/or prebiotics for antibiotic-reduced poultry. Poultry Science, 97(11), 3807-3815. https://doi.org/10.3382/ps/pey160

Alagawany, M., Abd El-Hack, M. E., Farag, M. R., Sachan, S., Karthik, K., \& Dhama, K. (2018). The use of probiotics as eco-friendly alternatives for antibiotics in poultry nutrition. Environmental Science and Pollution Research, 25(11), 10611-10618. https://doi.org/10.1007/s11356-018-1687-x

Alavi, S. A. N., Zakeri, A., Kamrani, B., \& Pourakbari, Y. (2012). Effect of prebiotics, probiotics, acidfire, growth promoter antibiotics and synbiotic on humural immunity of broiler chickens. Global Veterinaria, 8(6), 612-617.

Alexandrino, S. L. de S. A., Costa, T. F., Silva, N. G. D. da, Abreu, J. M. de, Silva, N. F. da, Sampaio, S. A., Christofoli, M., Cruz, L. C. F., Moura, G. F., Faria, P. P., \& Minafra, C. S. (2020). Microbiota intestinal e os fatores que influenciam na avicultura. Research, Society and Development, 9(6), e87963098. https://doi.org/10.33448/rsd-v9i6.3098

Antonialli, R. (2013). Efeito de ligantes de receptores semelhantes a Toll na resposta imune induzidas por antígenos direcionados ao DEC205 e DCIR2. 
Babu, U. S., Harrison, L. M., Patel, I. R., Ramirez, G. A., Williams, K. M., Pereira, M., \& Balan, K. V. (2016). Differential antibacterial response of chicken granulosa cells to invasion by Salmonella serovars. Poultry Science, 95(6), 1370-1379. https://doi.org/10.3382/ps/pew050

Ballou, A. L., Ali, R. A., Mendoza, M. A., Ellis, J. C., Hassan, H. M., Croom, W. J., \& Koci, M. D. (2016). Development of the chick microbiome: How early exposure influences future microbial diversity. Frontiers in Veterinary Science, 3(JAN), 1-12. https://doi.org/10.3389/fvets.2016.00002

Barros, M. R., Filho, R. L. A., Lima, E. T., \& Crocci, J. A. (2009). Avaliação in vitro da atividade inibitória de Lactobacillus spp., isolados do inglúvio e cecos de aves sobre Salmonella. Arquivo Brasileiro de Medicina Veterinaria e Zootecnia, 61(4), 863-868. https://doi.org/10.1590/S0102-09352009000400013

Bindels, L. B., Delzenne, N. M., Cani, P. D., \& Walter, J. (2015). Opinion: Towards a more comprehensive concept for prebiotics. Nature Reviews Gastroenterology and Hepatology, 12(5), 303-310. https://doi.org/10.1038/nrgastro.2015.47

BRASIL. (2015). Ministério da Agricultura, Pecuária e Abastecimento/Secretaria de Defesa Agropecuária. Instrução Normativa $n^{\circ} 44$, de 15 de dezembro de 2015: Regulamento técnico sobre aditivos para produtos destinados à alimentação animal. Brasília.

BRASIL. (2020). Ministério da Agricultura, Pecuária e Abastecimento/Secretaria de Defesa Agropecuária. Instrução Normativa $n^{\circ} 1$, de 13 de janeiro de 2020: Proibição em território nacional de aditivos melhoradores de desempenho que contenham antimicrobianos classificados como importantes na medicina humana. Brasília.

Carramaschi, I. N. (2019). Dípteros Muscoides como Veiculadores de Bactérias Resistentes aos Antimicrobianos. In Tese de Doutorado (Biodiversidade e Saude) - Fiocruz.

Castanon, J. I. R. (2007). History of the Use of Antibiotic as Growth Promoters in European Poultry Feeds. Poultry Science, 86(11), $2466-2471$. https://doi.org/10.3382/ps.2007-00249

Celi, P., Verlhac, V., Pérez Calvo, E., Schmeisser, J., \& Kluenter, A. M. (2019). Biomarkers of gastrointestinal functionality in animal nutrition and health. Animal Feed Science and Technology, 250(May), 9-31. https://doi.org/10.1016/j.anifeedsci.2018.07.012

Cheng, G., Dai, M., Ahmed, S., Hao, H., Wang, X., \& Yuan, Z. (2016). Antimicrobial Drugs in Fighting against Antimicrobial Resistance. Frontiers in Microbiology, 7(APR), 1-11. https://doi.org/10.3389/fmicb.2016.00470

Christofoli, M., Souza, C. S., Costa, T. F., Alexandrino, S. L. de S. A., Faria, P. P. de, Minafra-Rezende, C. S., Santos, F. R. dos, Minafra, C. S., \& Pereira, P. S. (2020). Microbiota intestinal benéfica e prejudicial na avicultura: Revisão. Research, Society and Development, 9(7), e43973667. https://doi.org/10.33448/rsd-v9i7.3667

Conly, J. M., \& Johnston, B. L. (2004). Coming full circle: From antibiotics to probiotics and prebiotics. Canadian Journal of Infectious Diseases, 15(3), 161163. https://doi.org/10.1155/2004/354909

Coppola, M. M., \& Turnes, C. G. (2004). Probiotics and immune response. Ciência Rural, 34(4), 1297-1303.

Crisol-Martínez, E., Stanley, D., Geier, M. S., Hughes, R. J., \& Moore, R. J. (2017). Understanding the mechanisms of zinc bacitracin and avilamycin on animal production: linking gut microbiota and growth performance in chickens. Applied Microbiology and Biotechnology, 101(11), 4547-4559. https://doi.org/10.1007/s00253-017-8193-9

Toledo, G. S. P., Costa, P. T. C., Da Silva, L. P., Pinto, D., Ferreira, P., \& Poletto, C. (2007). Desempenho de frangos de corte alimentados com dietas contendo antibiótico e/ou fitoterápico como promotores, adicionados isoladamente ou associados. Ciencia Rural, 37(6), 1760-1764. https://doi.org/10.1590/S0103-84782007000600040

Diaz, T. G., Branco, A. F., Jacovaci, F. A., Jobim, C. C., Daniel, J. L. P., Bueno, A. V. I., \& Ribeiro, M. G. (2018). Use of live yeast and mannanoligosaccharides in grain-based diets for cattle: Ruminal parameters, nutrient digestibility, and inflammatory response. PLoS ONE, 13(11), 1-15. https://doi.org/10.1371/journal.pone.0207127

Didari, T., Solki, S., Mozaffari, S., Nikfar, S., \& Abdollahi, M. (2014). A systematic review of the safety of probiotics. Expert Opinion on Drug Safety, 13(2), 227-239. https://doi.org/10.1517/14740338.2014.872627

FAO. (2016). Probiotics in animal nutrition. In Physiological reviews (Vol. 34, Issue 1). https://doi.org/10.1152/physrev.1954.34.1.25

FDA. (2018). Antimicrobials Sold or Distributed for Use in Food-Producing Animals. Center for Veterinary Medicine, 7(December 2019$), 1-25$.

Feitosa, T. J. de O., Silva, C. E. da, Souza, R. G. de, Lima, C. D. S., Gurgel, A. de C., Oliveira, L. L. G. de, Nóbrega, J. G. S. da, Carvalho Júnior, J. E. M. de, Melo, F. de O. de, Santos, W. B. M. dos, Feitoza, T. de O., Costa, T. F., Brandão, P. A., \& Minafra, C. S. (2020). Microbiota intestinal das aves de produção: revisão bibliográfica. Research, Society and Development, 9(5), e42952779. https://doi.org/10.33448/rsd-v9i5.2779

Forte, C., Manuali, E., Abbate, Y., Papa, P., Vieceli, L., Tentellini, M., Trabalza-Marinucci, M., \& Moscati, L. (2018). Dietary Lactobacillus acidophilus positively influences growth performance, gut morphology, and gut microbiology in rurally reared chickens. Poultry Science, 97(3), 930-936. https://doi.org/10.3382/ps/pex396

FRAGA, K. B. (2013). Descrição Morfométrica, Análise Parasitológica e Histológica do Intestino do Carcará (Caracara plancus, Miller, 1777).

Froebel, L. K., Jalukar, S., Lavergne, T. A., Lee, J. T., \& Duong, T. (2019). Administration of dietary prebiotics improves growth performance and reduces pathogen colonization in broiler chickens. Poultry Science, 98(12), 6668-6676. https://doi.org/10.3382/ps/pez537

Gadde, U., Kim, W. H., Oh, S. T., \& Lillehoj, H. S. (2017). Alternatives to antibiotics for maximizing growth performance and feed efficiency in poultry: A review. Animal Health Research Reviews, 18(1), 26-45. https://doi.org/10.1017/S1466252316000207

Gast, R. K., Jones, D. R., Guraya, R., Anderson, K. E., \& Karcher, D. M. (2020). Research Note: Horizontal transmission and internal organ colonization by 
Salmonella Enteritidis and Salmonella Kentucky in experimentally infected laying hens in indoor cage-free housing. Poultry Science, 99(11), 6071-6074. https://doi.org/10.1016/j.psj.2020.08.006

Gibson, G. R., \& Roberfroid, M. B. (1995). Dietary Modulation of the Human Colonic Microbiota: Introducing the Concept of Prebiotics. The Journal of Nutrition, 125(6), 1401-1412. https://doi.org/10.1093/jn/125.6.1401

Gogineni, V. K., Morrow;, L. E., Gregory;, P. J., \& Malesker, M. A. (2013). Probiotics: History and Evolution. Journal of Ancient Diseases \& Preventive Remedies, 01(02), 1-7. https://doi.org/10.4172/2329-8731.1000107

Gong, J., Si, W., Forster, R. J., Huang, R., Yu, H., Yin, Y., Yang, C., \& Han, Y. (2007). 16S rRNA gene-based analysis of mucosa-associated bacterial community and phylogeny in the chicken gastrointestinal tracts: from crops to ceca. FEMS Microbiology Ecology, 59(1), 147-157. https://doi.org/10.1111/j.1574-6941.2006.00193.x

Gonzales, E., Mello, H. H. D. C., \& Café, M. B. (2012). Uso de antibióticos promotores de crescimento na alimentação e produção animal. Revista UFG, 13(1), 48-53. https://www.proec.ufg.br/up/694/o/13_07.pdf

Guimarães, D. O., Da Silva Momesso, L., \& Pupo, M. T. (2010). Antibióticos: Importância terapêutica e perspectivas para a descoberta e desenvolvimento de novos agentes. Quimica Nova, 33(3), 667-679. https://doi.org/10.1590/S0100-40422010000300035

Harwood, C. R., Mouillon, J.-M., Pohl, S., \& Arnau, J. (2018). Secondary metabolite production and the safety of industrially important members of the Bacillus subtilis group. FEMS Microbiology Reviews, 42(6), 721-738. https://doi.org/10.1093/femsre/fuy028

Hume, M. E. (2011). Historic perspective: Prebiotics, probiotics, and other alternatives to antibiotics. Poultry Science, 90(11), 2663-2669. https://doi.org/10.3382/ps.2010-01030

Iannitti, T., \& Palmieri, B. (2010). Therapeutical use of probiotic formulations in clinical practice. Clinical Nutrition, 29(6), 701-725. https://doi.org/10.1016/j.clnu.2010.05.004

Jha, R., Das, R., Oak, S., \& Mishra, P. (2020). Probiotics (Direct-Fed Microbials) in Poultry Nutrition and Their Effects on Nutrient Utilization, Growth and Laying Performance, and Gut Health: A Systematic Review. Animals, 10(10), 1863. https://doi.org/10.3390/ani10101863

Jiang, S., Mohammed, A. A., Jacobs, J. A., Cramer, T. A., \& Cheng, H. W. (2019). Effect of synbiotics on thyroid hormones, intestinal histomorphology, and heat shock protein 70 expression in broiler chickens reared under cyclic heat stress. Poultry Science, 99(1), 142-150. https://doi.org/10.3382/ps/pez571

Jones, F. T., \& Ricke, S. C. (2003). Observations on the history of the development of antimicrobials and their use in poultry feeds. Poultry Science, 82(4), 613-617. https://doi.org/10.1093/ps/82.4.613

Khan, S., Moore, R. J., Stanley, D., \& Chousalkar, K. K. (2020). The gut microbiota of laying hens and its manipulation with prebiotics and probiotics to enhance gut health and food safety. Applied and Environmental Microbiology, 86(13), 1-18. https://doi.org/10.1128/AEM.00600-20

Klaenhammer, T. R., \& Kullen, M. J. (1999). Selection and design of probiotics. International Journal of Food Microbiology, 50(1-2), 45-57. https://doi.org/10.1016/S0168-1605(99)00076-8

Kogut, M. H. (2019). The effect of microbiome modulation on the intestinal health of poultry. Animal Feed Science and Technology, 250(February 2018), 3240. https://doi.org/10.1016/j.anifeedsci.2018.10.008

Kridtayopas, C., Rakangtong, C., Bunchasak, C., \& Loongyai, W. (2019). Effect of prebiotic and synbiotic supplementation in diet on growth performance, small intestinal morphology, stress, and bacterial population under high stocking density condition of broiler chickens. Poultry Science, 98(10), 4595-4605. https://doi.org/10.3382/ps/pez152

Kuritza, L. N., Westphal, P., \& Santin, E. (2014). Probióticos na avicultura. Ciencia Rural, 44(8), 975-979. https://doi.org/10.1590/0103-8478cr20120220

Lan, R. X., Lee, S. I., \& Kim, I. H. (2017). Effects of Enterococcus faecium SLB 120 on growth performance, blood parameters, relative organ weight, breast muscle meat quality, excreta microbiota shedding, and noxious gas emission in broilers. Poultry Science, 96(9), 3246-3253. https://doi.org/10.3382/ps/pex101

Lemos, M. J. de, Calixto, L. F. L., Torres-Cordido, K. A. A., \& Reis, T. L. (2016). Uso de aditivo alimentar equilibrador da flora intestinal em aves de corte e de postura. Arquivos Do Instituto Biológico, 83(0), 1-7. https://doi.org/10.1590/1808-1657000862014

Macari, M., Lunedo, R., Pedroso, A. (2014). Microbiota intestinal de aves. In Produção de Frangos de Corte (Issue June, p. 565).

Macedo, L. L., Vimercati, W. C., \& Araújo, C. da S. (2020). Fruto-oligossacarídeos: aspectos nutricionais, tecnológicos e sensoriais. Brazilian Journal of Food Technology, 23(0), 1-9. https://doi.org/10.1590/1981-6723.08019

Maity, T. .;, \& Misra, A. . (2009). Probiotics and Human Health: Synoptic Review. African Journal Of Food Agriculture Nutrition And Development, 9(8), $31-47$.

Matur, E., Ergul, E., Akyazi, I., Eraslan, E., \& Cirakli, Z. T. (2010). The effects of Saccharomyces cerevisiae extract on the weight of some organs, liver, and pancreatic digestive enzyme activity in breeder hens fed diets contaminated with aflatoxins. Poultry Science, 89(10), 2213-2220. https://doi.org/10.3382/ps.2010-00821

Mendes, F. R., Leandro, N. S. M., Andrade, M. A., Cafe, M. B., Santana, E. S., \& Stringhini, J. H. (2014). Qualidade bacteriológica de ovos contaminados com Pseudomonas aeruginosa e armazenados em temperatura ambiente ou refrigerados. Ciência Animal Brasileira, 15(4), 444-450. https://doi.org/10.1590/1089-6891v15i431244

Murarolli, V. . (2008). Efeito de prebiótico, probiótico e simbiótico sobre o desempenho, morfologia intestinal e imunidade de frangos de corte.

Silva, E.N., \& Filho, R.L.A. (2000). Probióticos E Prebióticos Na Avicultura. II Simpósio de Sanidade Avícola, 2(0), $45-55$. 
O’Donnell, J. A., Gelone, S. P., \& Safdar, A. (2015). Topical Antibacterials. In Mandell, Douglas, and Bennett's Principles and Practice of Infectious Diseases (Eighth Edi, Vol. 1). Elsevier Inc. https://doi.org/10.1016/B978-1-4557-4801-3.00037-0

Ocejo, M., Oporto, B., \& Hurtado, A. (2019). 16S rRNA amplicon sequencing characterization of caecal microbiome composition of broilers and free-range slow-growing chickens throughout their productive lifespan. Scientific Reports, 9(1), 1-14. https://doi.org/10.1038/s41598-019-39323-x

Pan, D., \& Yu, Z. (2013). Intestinal microbiome of poultry and its interaction with host and diet. Gut Microbes, 5(1), 37-41. https://doi.org/10.4161/gmic.26945

Pavli, V., \& Kmetec, V. (2006). Pathways of Chemical Degradation of Polypeptide Antibiotic Bacitracin. Biological \& Pharmaceutical Bulletin, 29(11), 2160-2167. https://doi.org/10.1248/bpb.29.2160

Pender, C. M., Kim, S., Potter, T. D., Ritzi, M. M., Young, M., \& Dalloul, R. A. (2016). In ovo supplementation of probiotics and its effects on performance and immune-related gene expression in broiler chicks. Poultry Science, 96(5), 1052-1062. https://doi.org/10.3382/ps/pew381

Pourabedin, M., \& Zhao, X. (2015). Prebiotics and gut microbiota in chickens. FEMS Microbiology Letters, 362(15), 1-23. https://doi.org/10.1093/femsle/fnv122

Raghuwanshi, S., Misra, S., Sharma, R., \& Bisen, P. S. (2015). Indian perspective for probiotics : A review. Indian J Dairy Sci, 68(3), $195-205$.

Raizel, R., Santini, E., Kopper, A. M., \& Reis Filho, A. D. (2011). Effects of probiotics, prebiotics and synbiotics consumption on the human organism organism. Ciência \& Saúde, 4(2), 66-74.

Rehman, A., Arif, M., Sajjad, N., Al-Ghadi, M. Q., Alagawany, M., Abd El-Hack, M. E., Alhimaidi, A. R., Elnesr, S. S., Almutairi, B. O., Amran, R. A., Hussein, E. O. S., \& Swelum, A. A. (2020). Dietary effect of probiotics and prebiotics on broiler performance, carcass, and immunity. Poultry Science, 99(12), 6946-6953. https://doi.org/10.1016/j.psj.2020.09.043

Reis, T. L., \& Vieites, F. M. (2019). Antibiótico, Prebiótico, Probiótico E Simbiótico Em Rações De Frangos De Corte E Galinhas Poedeiras. Ciência Animal, 29(3), 133-147.

Ricke, S. C. (2015). Potential of fructooligosaccharide prebiotics in alternative and nonconventional poultry production systems. Poultry Science, 94(6), 14111418. https://doi.org/10.3382/ps/pev049

Ricke, Steven C., Lee, S. I., Kim, S. A., Park, S. H., \& Shi, Z. (2020). Prebiotics and the poultry gastrointestinal tract microbiome. Poultry Science, 99(2), 670-677. https://doi.org/10.1016/j.psj.2019.12.018

Roselli, M., Finamore, A., Britti, M. S., Bosi, P., Oswald, I., \& Mengheri, E. (2005). Alternatives to in-feed antibiotics in pigs: Evaluation of probiotics, zinc or organic acids as protective agents for the intestinal mucosa. A comparison of in vitro and in vivo results. Animal Research, 54(3), 203-218. https://doi.org/10.1051/animres:2005012

Shang, Y., Kumar, S., Thippareddi, H., \& Kim, W. K. (2018). Effect of dietary fructooligosaccharide (FOS) supplementation on ileal microbiota in broiler chickens. Poultry Science, 97(10), 3622-3634. https://doi.org/10.3382/ps/pey131

Sidjabat, H. E., \& Blackall, L. . (2020). One health probiotics. Microbiology Australia, 97(3), 1006-1021. https://doi.org/10.3382/ps/pex359

Siewert, G., \& Strominger, J. L. (1967). Bacitracin: An Inhibitor of the Dephosphorylation of Lipid pyrophosphate, An Intermediate in the Biosynthesis of the Peptidoglycan of Bacterial Cell Walls. Proceedings of the National Academy of Sciences, 57(3), 767-773. https://doi.org/10.1073/pnas.57.3.767

Silbergeld, E. K., Graham, J., \& Price, L. B. (2008). Industrial food animal production, antimicrobial resistance, and human health. Annual Review of Public Health, 29(0), 151-169. https://doi.org/10.1146/annurev.publhealth.29.020907.090904

Soccol, C. R., Vandenberghe, L. P. de S., Spier, M. R., Medeiros, A. B. P., Yamaguishi, C. T., De Dea Lindner, J., Pandey, A., \& Thomaz-Soccol, V. (2010). The potential of probiotics: A review. Food Technology and Biotechnology, 48(4), 413-434.

STOKSTAD, E. L., \& JUKES, T. H. (1949). The multiple nature of the animal protein factor. The Journal of Biological Chemistry, 180(2), 647-654. https://doi.org/10.1016/s0021-9258(18)56683-7

Swanson, K. S., Gibson, G. R., Hutkins, R., Reimer, R. A., Reid, G., Verbeke, K., Scott, K. P., Holscher, H. D., Azad, M. B., Delzenne, N. M., \& Sanders, M. E. (2020). The International Scientific Association for Probiotics and Prebiotics (ISAPP) consensus statement on the definition and scope of synbiotics. Nature Reviews Gastroenterology and Hepatology, 17(11), 687-701. https://doi.org/10.1038/s41575-020-0344-2

Światkiewicz, S., Arczewska-Włosek, A., \& Józefiak, D. (2014). Immunomodulatory efficacy of yeast cell products in poultry: A current review. World’s Poultry Science Journal, 70(1), 57-68. https://doi.org/10.1017/S0043933914000051

Teng, P. Y., \& Kim, W. K. (2018). Review: Roles of prebiotics in intestinal ecosystem of broilers. Frontiers in Veterinary Science, 5(OCT), 1-18. https://doi.org/10.3389/fvets.2018.00245

Thema, K., Mlambo, V., Snyman, N., \& Mnisi, C. M. (2019). Evaluating alternatives to zinc-bacitracin antibiotic growth promoter in broilers: Physiological and meat quality responses. Animals, 9(12). https://doi.org/10.3390/ani9121160

Threlfall, E. J., Ward, L. R., Frost, J. A., \& Willshaw, G. A. (2000). The emergence and spread of antibiotic resistance in food-borne bacteria. International Journal of Food Microbiology, 62(1-2), 1-5. https://doi.org/10.1016/S0168-1605(00)00351-2

Tiwari, G., Tiwari, R., Pandey, S., \& Pandey, P. (2012). Promising future of probiotics for human health: Current scenario. Chronicles of Young Scientists, 3(1), 17. https://doi.org/10.4103/2229-5186.94308 
Research, Society and Development, v. 10, n. 10, e242101018800, 2021

(CC BY 4.0) | ISSN 2525-3409 | DOI: http://dx.doi.org/10.33448/rsd-v10i10.18800

Van Goor, A., Redweik, G. A. J., Stromberg, Z. R., Treadwell, C. G., Xin, H., \& Mellata, M. (2020). Microbiome and biological blood marker changes in hens at different laying stages in conventional and cage free housings. Poultry Science, 99(5), 2362-2374. https://doi.org/10.1016/j.psj.2020.01.011

WHO. (1997). The medical impact of antimicrobial use in food animals. World Health Organization, 24. https://doi.org/10.1007/s00406-011-0255-x

Yadav, S., \& Jha, R. (2019). Strategies to modulate the intestinal microbiota and their effects on nutrient utilization, performance, and health of poultry. Journal of Animal Science and Biotechnology, 10(1), 1-11. https://doi.org/10.1186/s40104-018-0310-9 